\title{
The effect of social media on English second language essay writing with special reference to WhatsApp
}

\begin{tabular}{|c|c|}
\hline \multicolumn{2}{|c|}{$\begin{array}{l}\text { Authors: } \\
\text { Sister L. Songxaba }{ }^{1} \text { (1) } \\
\text { Limkani Sincuba }{ }^{1} \text { (1) }\end{array}$} \\
\hline \multicolumn{2}{|c|}{$\begin{array}{l}\text { Affiliations: } \\
\text { }{ }^{1} \text { Department of Continuing } \\
\text { Professional Teacher } \\
\text { Development, Faculty of } \\
\text { Educational Sciences, Walter } \\
\text { Sisulu University, Mthatha, } \\
\text { South Africa }\end{array}$} \\
\hline \multicolumn{2}{|c|}{$\begin{array}{l}\text { Corresponding author: } \\
\text { Sister Songxaba, } \\
\text { slsongxaba@gmail.com }\end{array}$} \\
\hline \multicolumn{2}{|c|}{$\begin{array}{l}\text { Dates: } \\
\text { Received: } 04 \text { Oct. } 2017 \\
\text { Accepted: } 20 \text { May } 2019 \\
\text { Published: } 30 \text { July } 2019\end{array}$} \\
\hline \multicolumn{2}{|c|}{$\begin{array}{l}\text { How to cite this article: } \\
\text { Songxaba, S.L. \& Sincuba, L., } \\
2019, \text { 'The effect of social } \\
\text { media on English second } \\
\text { language essay writing } \\
\text { with special reference } \\
\text { to WhatsApp', Reading } \\
\text { \& Writing 10(1), a179. } \\
\text { https://doi.org/10.4102/ } \\
\text { rw.v10i1.179 }\end{array}$} \\
\hline \multicolumn{2}{|c|}{$\begin{array}{l}\text { Copyright: } \\
\text { ( } 2019 \text {. The Authors. } \\
\text { Licensee: AOSIS. This work } \\
\text { is licensed under the } \\
\text { Creative Commons } \\
\text { Attribution License. }\end{array}$} \\
\hline \multicolumn{2}{|l|}{ Read online: } \\
\hline 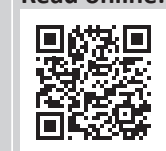 & $\begin{array}{l}\text { Scan this QR } \\
\text { code with your } \\
\text { smart phone or } \\
\text { mobile device } \\
\text { to read online. }\end{array}$ \\
\hline
\end{tabular}

Background: The Eastern Cape province in South Africa is a multilingual province where isiXhosa is the most widely spoken indigenous language. Learners seldom use English at home, and it remains, largely, the language of learning and teaching used at school. With the advent of dynamic technology, learners are widely exposed to social media, and those who use the language of social media networks tend to include it in their academic activities at school.

Objectives: The purpose of this article is to report on the orthographic errors in English Second Language Grade 10 essay writing caused by the use of social media, particularly WhatsApp.

Method: The study was carried out at three randomly selected high schools in one district in the Eastern Cape province, South Africa. The study used a quantitative approach to data analysis, but with a survey research design. Random sampling techniques were used to select 180 learners from three schools. The data collection instrument consisted of learners' narrative essays. The data were analysed quantitatively and are presented using tables and graphs. The orthographic errors in the essays were identified and quantified.

Results: The findings of this investigation shed light on the influence of social media on learners' writing. Some of the findings included use of abbreviations, unnecessarily shortened words, and use of numbers instead of the complete word form.

Conclusion: Recommendations are made on how teachers can help learners avoid this erroneous use of language in their writing. Suggestions are also made on how textbook writers and the Department of Basic Education can assist and support teachers in this process.

Keywords: Orthographic errors; social media; essay; WhatsApp; English second language.

\section{Introduction}

Language is a systematic means of communicating ideas using sounds, gestures, signs or marks. It is the code used to express oneself and communicate with others. Communicating is to share information, or to share what one knows and to interact with others. It involves a system of combining words to create meaning. Thus communication involves language, and language, therefore, remains potentially a communicative medium capable of expressing ideas and concepts as well as moods, feelings and attitudes (Habermas 1979).

Language is not merely a tool that helps human beings express thoughts and feelings but is also a way of becoming civilised. It is an important link in today's world of globalisation. Writing is a way of communicating and conveying ideas and feelings from one mind to another mind. The hallmarks of good writing are the hallmarks of good communication. The skill of writing is developed through composition writing (Swain 2005). Essay writing forms a fundamental tool in second language learning. This is evidenced by the highest marks allocated to the essay (Paper 3) during the examination of English Second Language (ESL) from Grade 10 to 12 in South Africa's Curriculum Assessment Policy Statement (CAPS) (Department of Basic Education 2015). At the same time development and technological advancement has seen writing of formal English on the decline and much of this is attributed to WhatsApp communication.

Writing is an 'intricate' and complex task; it is the 'most difficult of the language abilities to acquire' (Allen \& Corder 1974:177). Its level of difficulty varies between native speakers who think in the language being used and non-native speakers who think in their own native language (Allen \& Corder 1974:177). While writing, non-native speakers have, in general, to think about rules they need to apply; rules that native speakers are supposed to have automatised. 
Jabeen (2015) asserts that people learn languages when they have opportunities to understand and work with language in a context that they comprehend and find interesting.

Alsaawi (2015) states that writing is a method that transfers spoken language from being heard to being seen and consequently read. In order to represent spoken language in a written script, a system must be invented and for that reason precisely implemented. Thus, the formal English writing system is the one that native speakers and second language learners should strictly follow.

Jabeen (2015:15) says that English is the predominant foreign language taught in schools in Europe, South America, Asia and Africa. It is suggested that English is more widely spoken and written than any other language, even more than Latin has ever been. It is also suggested that English might now be the first truly global language, being the dominant or official language in over 60 countries. In South Africa, English is used in education, administration and mass media. The English language as stated is one of the most widely spoken languages in the world (Akinwamide 2012). Furthermore, Padilla and McElroy (2005) as well as Villareal and Van der Horst (2008) state that the labour market demands that professionals have at least a basic knowledge of the English language to get a job with an income that ameliorates their socio-economic status. Therefore, if English is used inappropriately and incorrectly in essays, for example the use of WhatsApp language, it might pose communication difficulties for the learners who write them and for their educators who read them.

If learners have a habit of using social media such as WhatsApp language in their day-to-day writing, then they may not be able to write appropriately in formal job situations. Roelofse (2013) contends that exposure to new literacies found in new technologies undoubtedly impacts the way in which second language learners perceive the world. Furthermore, the amount of contact with these social utilities certainly influences literacy practices by learners. New technologies do not merely alter the way people live their lives but it affects the way they think. Moreover, Davies (2012:21) in Roelofse (2013) argues that 'texts of the new technologies have mutated into complex hybrid systems that have made new demands on reading and writing, viewing, social exchange, and communication'. Facebook is no exception in that the use of this social network site requires a multimodal approach of embedding and combining words and written texts from numerous sites. In the same sense, the social medium, WhatsApp is perceived by the researchers as having the same contaminating effect on learners' essay writing skills. In this regard, social media is a 'dialogue' and 'means [of] engaging with people' (Coons 2012:44). In support of this argument Roelofse's (2013) research emphasises the alterations in written communication brought about by transformation in electronic media communication in the use of Facebook. Roelofse collected data from educators to substantiate the argument that there is a significant and measurable effect of social media and this is articulated in the question: 'Have you witnessed any grammatical errors in written work that could be attributed to Facebook-speak?' Two out of the five educator participants answered "agree" and the remaining three answered "strongly agree". When asked to specify, the teachers were given a space to identify more precisely the kinds of errors found in learners' work. Teacher $\mathrm{N}$ stated that, 'learners' language use is so poor that they cannot express themselves. The use of the wrong verb often changes the meaning of a fact'. Teacher $M$ stated: 'Students shorten words and sentences. They don't start sentences with capitals and forget about punctuation'. Teacher D wrote that 'spelling and the answering of questions in as short as possible ways with incorrect spelling was evidenced'. Finally, Teacher P observed that 'learners like to use abbreviations for certain words that are commonly used with electronic media such as "u" or "lol".'

David (2001), Cai (2001) and Dovey (2010) concluded from their study that writing is an important tool in education and in the working environment, hence it is important that it is not polluted by social media scripts such as WhatsApp. Social media language generally pollutes grammar, spelling and sentence construction to name but a few aspects of writing. Such errors in writing are said to pollute the text. Norrish (1987:7) defines an error as a systematic deviation when a learner has not learnt something and consistently gets it wrong. Cunningworthy (1995:87) concurs and adds that errors are systematic deviations from the norms of the language being learned. These two scholars use the phrase 'systematic deviation' in their definitions of an error which can be interpreted as a deviation that happens repeatedly. Errors can also be classified as inter-lingual or intra-lingual (Richards \& Schmidt 2002:267).

Inter-lingual errors can be identified as transfer errors that result from a learner's first language features, for example grammatical, lexical or pragmatic errors. On the other hand, intra-lingual errors are overgeneralisations (Richards \& Schmidt 2002:379) in the target language, resulting from ignorance of rule restrictions, incomplete applications of rules, and false concepts hypothesised. Orthography is the correct way of writing a particular language. The term orthography comes from the Greek language and means 'correct way of writing'. The conventional spelling system of a language is therefore part of its orthography. Orthography is the standardised procedure of a writing system, which includes spelling, pronunciation, word break and emphasis. Punctuation, word break and emphasis are not major problems for learners, but spelling is a problem for the majority of learners. In the English language, spelling plays an important role in the writing process (Franklin 2014). Languages have either deep or shallow orthographies. If a sentence has incorrectly spelt words, the meaning and message of the sentence may be distorted. For precise meaning and precise communication words need to be spelt correctly. Frequent use of wrongly spelt words in an essay 
may erode the direct intended meaning of communication. WhatsApp may promote word cutting and such word cuts may be confusing for different people and even be meaningless for some readers. WhatsApp's casual means of communication may lead to the decay of formal essay writing skills. The efforts of linguists are to perfect and sharpen language efficiency; therefore, WhatsApp language has to be closely monitored so that it does not have a negative influence on the essays written by learners. Short word writing by learners may be viewed by linguists and language teachers as a decline of language proficiency in writing.

Forms of WhatsApp text messaging mostly involve the use of pictograms and logograms. Words are either shortened by using symbols to represent the word, or using symbols whose names sound like a syllable of the word. A text may consist of words or an alphanumeric combination. For example, texting 'to date' could be rendered as ' $2 d 8^{\prime}$ ', 'for you' as ' $4 U^{\prime}$ ' and 'before' as ' $b 4$ '. To text 'to whom it may concern', for example, one could simply write 'twimc'. 'Love you with all my heart' could also be texted as 'luwamh' (BBC Focus on Africa 2006:25). The impact of social media writing was also observed in students' academic writing by Jabeen (2015:58-59). Jabeen reported that many factors were responsible for affecting a learner's language. One such phenomenon which was also analysed in the study was the use of short wording in the writing that is not allowed in formal writing. Examples of some of these words were: plz for please, $b / w$ for between, $\mathcal{E}$ for and, $b 4$ for before, thn $x$ for thanks and thanku for thank you. Many other such mistakes are found in the analysis of the errors. The study also highlights the phenomenon of social media language being used so frequently that students use it unconsciously in their academic writing (Jabeen 2015).

Several syllables of a word can also be substituted by using numerical sequences. It is also possible to use numbers alone to communicate a whole passage. Such writing may erode the progressions of grammar, spelling and good sentence construction in formal English writing. It seems that WhatsApp language may influence or become predominant in learners' communication, if not dealt with. Learners using English as a second language may not be able to write correctly and appropriately in English, if their writing is highly influenced by WhatsApp language.

Allaith and Joshi (2011) point out that literacy is appraised not only by reading and writing accuracy, but also by the correct spelling of words. Spelling mastery indicates one's level of education while spelling errors reveal inaccuracy.

Nesamalar, Saratha and Teh (2001) point out that learners' writing skill deficiencies are a cause for concern among academics and parents, considering that their writing component is given higher credit (marks) in school examinations. Writing of essays, therefore, has to be given more attention so that negative influences such as WhatsApp and other social media do not impact negatively on the academic writing of learners.

\section{Goals of the study}

This article sought to investigate the effect of WhatsApp on orthographic errors in ESL essay writing. The study was part of a larger study on orthographic errors in ESL learning. Against this background, the researchers sought to investigate the influence of social media such as WhatsApp on learners' orthographic errors in essay writing. To this end, the study aimed to address the following research question: To what extent does WhatsApp influence the predominance of orthographic errors in English Second Language learners' essay writing?

\section{Methodology}

Songxaba (2016:63) states that methodology culminates in techniques and procedures or processes used in the process of gathering data. Methodology means the philosophy of the research process. The article adopted a quantitative approach to data analysis, but used a survey as the data collection tool. This methodology benefits the article because the researchers sought a more objective tool to investigate this phenomenon. As Njobe (1992) states:

... analysis based on statistical computations is seen as being more objective. In the latter the researcher is being more guided by the outcome of the statistical computations even against [his or her] own wishes and beliefs. (p. 23)

Leedy and Ormrod (2005:105) shed light on this notion when they explain that quantitative research deals with human problems based on testing a theory composed of variables, measured in numbers and analysed using statistical procedures. Terre Blanche, Durrheim and Painter (2011:563) concur, saying that quantitative research is research in which data are collected or coded into numerical forms, and to which statistical analyses may be applied to determine the significance of the findings. Quantitative research involves the counting and measuring of events and performing a statistical analysis of a body of numerical data (Burke \& Larry 2008). The assumption behind quantitative research is that there is an objective truth in the world that can be measured and explained scientifically (Babbie \& Mouton 2001:233). Above all, quantitative data can be easily summarised and it is this that facilitates the communication of findings.

A survey research design was followed in this research, as data were collected through surveys. The research sites were not named so as to protect their identity, and codes were given to their names: $X, Y$ and $Z$.

The researchers gathered information on orthographic errors in English First Additional Language (ENG FAL) essay writing of Grade 10 learners. The researchers used quantitative research so as to probe the current use of WhatsApp. In order to identify and determine the use of WhatsApp language, the researchers counted the mistakes and errors made by the participants. Data collected were analysed and the results were presented in tables, figures and graphs. To quantify the errors committed, pie chart graphs were used to present the 
data collected. On the pie charts the errors committed by the respondents were shown using percentages. Special emphasis was placed on the influence of WhatsApp writing on orthographic errors made by the three groups of participants from research schools $\mathrm{X}, \mathrm{Y}$ and $\mathrm{Z}$.

\section{Population and sample}

A sample of 522 Grade 10 learners from three senior secondary schools (namely X, Y and Z for the purposes of this study) constituted the population for this article. The three schools were randomly selected from one district in the Eastern Cape, South Africa. All the participants in each research site were given numbers from 1 to 80 . Every fourth number from research sites $\mathrm{X}$ and $\mathrm{Z}$ was taken as a participant for this research article. However, in research site $\mathrm{Y}$ every second number was taken since they were fewer learners doing Grade 10. Thus a sample of 180 participants in Grade 10 was randomly selected from the three schools. The number of participants from each research site is shown in Table 1.

\section{Instrumentation}

Data were collected using narrative essays written by the learners in English. The learners were given five narrative essay topics to choose from and wrote an essay on the topic of their choice. The respondents wrote the essays following the stipulated essay writing rules taught in the class, namely mind-mapping, first draft, proofreading, making corrections and final work. The written work was done and submitted via the WhatsApp platform. The learners are taught narrative essay writing skills in ESL from Grade 3 in South African schools. Five topics were given in each research site. These topics were:

- 'I thought my life had ended'

- 'When I open the door'

- 'My life was a mess'

- 'I never thought the friend I trusted would be the one'

- 'When I opened my eyes'

The learners were asked to write $250-300$ words in $2 \mathrm{~h}$ in their respective sites under the supervision of their ENG FAL teacher during school hours.

\section{Ethical considerations}

Permission to carry out the study was obtained from the provincial Department of Basic Education of South Africa. The respondents gave informed consent in writing by filling in a form provided by the university. Permission from the three schools was given in writing by the principals of those schools. Confidentiality was guaranteed by the researcher as respondents did not write their names on the essays. Codes were used in

TABLE 1: Number of participants per research site.

\begin{tabular}{lc}
\hline Research site & Number of participants (N) \\
\hline$X$ & 70 \\
$Y$ & 60 \\
$Z$ & 50 \\
\hline Total & $\mathbf{1 8 0}$ \\
\hline
\end{tabular}

alphabetical order to identify essays submitted, as such data collected could not be linked to respondents. Consent was sought from the participants of the three researched schools in the Eastern Cape and from the parents of the learners under 18 years of age. It was explained to the participants that they had the voluntary right to take part or withdraw from participating at any time of this research.

\section{Data analysis}

The submitted essays were marked by the researchers and analysed manually by the same researchers. Errors identified were classified according to use of WhatsApp language error (WLE), WhatsApp language error use of numbers (WLN) and use of words with letters that were omitted. Graphs and tables were used to present the data. Pie charts showing percentages of the errors identified were also used. An explanation was given under each aspect of data using tables and graphs.

\section{Results}

The following observations were made regarding the impact of WhatsApp on respondents' academic essay writing.

\section{Use of WhatsApp language errors}

Table 2 shows some of the sentences written by the respondents using WhatsApp language in the essays they wrote.

Table 2 shows that respondents resorted to WhatsApp language in writing certain sentences in the essays given. For example, learners wrote: 'My dad was (@) work' instead of [at], while some wrote 'I (wz) not full' instead of writing [was].

\section{WhatsApp language error use of numbers}

Respondents wrote numbers instead of writing words where applicable. Table 3 has some examples written by the respondents.

TABLE 2: WhatsApp language error committed by respondents in this study.

\begin{tabular}{ll}
\hline Error & Correction \\
\hline My dad was (@) work & [at] \\
I (wz) not full... & [was] \\
We went to a (frnd'z) house & [friend's] \\
It was a hot (sny) (dy) & [sunny] [day] \\
I brushed my (tth) & [teeth] \\
I asked (mi) (frndz) (2) (cm) over & [my] [friends] [to] [come] \\
She (wz) a (bg) (pt) of (mi) (lyf) & [was] [big] [part] [my] [life] \\
I remember (ths) (crzy) (lafs) & [those] [crazy] [laughter] \\
(Thy wld brg fd 4 mi) & [They would bring me food] \\
I (wz afd bcz) I (wz aln) & [was afraid because] [was alone] \\
\hline
\end{tabular}

TABLE 3: WhatsApp language error use of numbers.

\begin{tabular}{ll}
\hline Error & Correction \\
\hline It (wz mi $1 \mathrm{tm})$ & [was my first time] \\
I (ws thkg tht $2 \mathrm{dy} \mathrm{...)}$ & [was thinking that today] \\
(Jxt b4) we (Ift) & [Just before] [left] \\
\hline
\end{tabular}


Table 3 shows that respondents used numbers instead of words when writing for example; 'It (wz mi $1 \mathrm{tm}$ )' [It was my first time], 'I (ws thkg tht $2 \mathrm{dy}$...)' [I was thinking that today], '(Jxt 64 we lft)' [Just before we left].

\section{WhatsApp words used by the learners}

Respondents used words with letters that were omitted and were mostly used in WhatsApp language.

Learners' use of a number of words from WhatsApp language in some cases made reading and making sense of their written essays difficult. For example, some of the words they wrote were: 'hi /he, slp/sleep, wen/when, nvr/ never, dat/that, de/the', as shown by a few of the examples in Table 4 and types of predominant orthographic errors in Figure 1.

\section{Respondents' frequencies of spelling orthographic errors}

Figure 2 presents frequencies of spelling orthographic errors among the participants in this article. The data for this graph were drawn from Table 4.

Respondent 42 from school Z (Z42) had the highest number of spelling errors committed, followed by respondent 50 from school $X(X 50)$ and respondent 5 from school $Y(Y 5)$ which had an average level of spelling errors. However, respondent 1 from school $X(X 1)$ and respondent 42 from school Y (Y42) had the lowest spelling errors committed in this study, as shown in Figure 2.

\begin{tabular}{ll}
\multicolumn{2}{l}{ TABLE 4: WhatsApp words used by the learners in their written essays. } \\
\hline Error & Correction \\
\hline Slp & [sleep] \\
$\mathrm{Nt}$ & [not] \\
$\mathrm{Gt}$ & [get/got] \\
$\mathrm{Nvr}$ & {$[$ never] } \\
$\mathrm{De}$ & [the] \\
$\mathrm{N}$ & [and] \\
$\mathrm{Dat}$ & [that] \\
$\mathrm{Wr}$ & [write/right/wrong] \\
$\mathrm{Coz}$ & [cause] \\
$\mathrm{Hi}$ & {$[$ his/ he] } \\
Wen & [when] \\
\hline
\end{tabular}

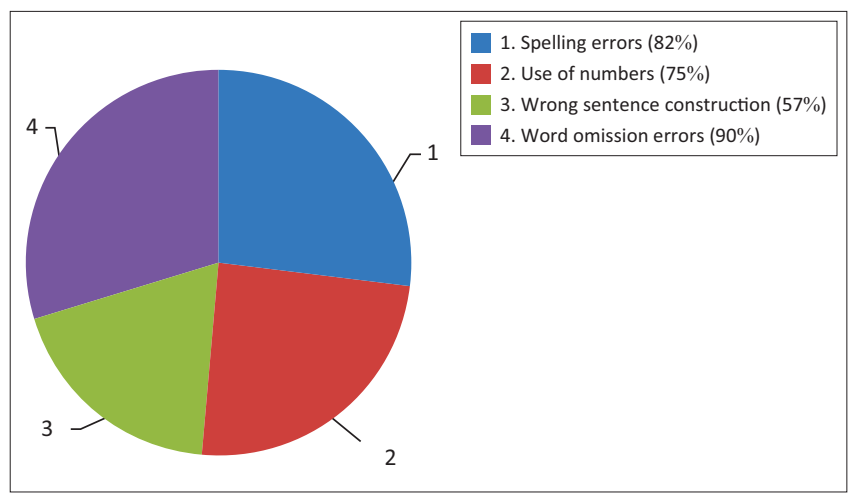

FIGURE 1: Types of predominant orthographic errors frequency.

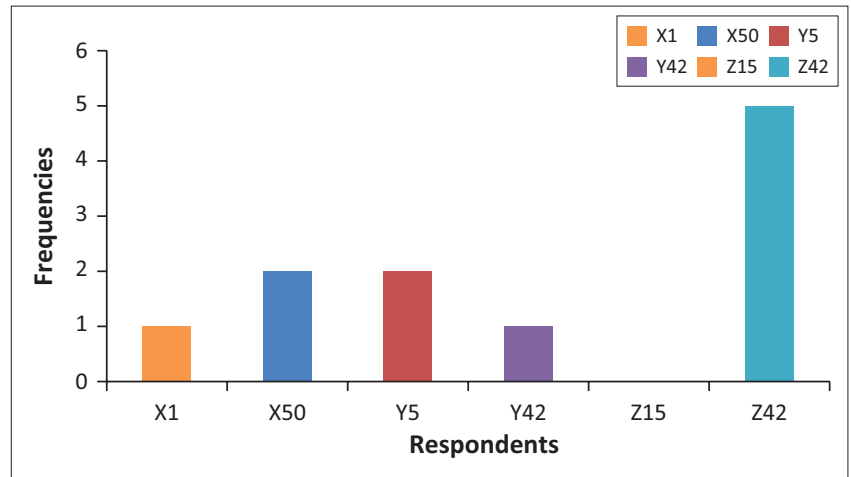

$\mathrm{X} 1$, respondent 1 from school $\mathrm{X} ; \mathrm{X} 50$, respondent 50 from school $\mathrm{X} ; \mathrm{Y} 5$, respondent 5 from school Y; Y42, respondent 42 from school Y; Z15, respondent 15 from school Z; Z42, respondent 42 from school $Z$.

FIGURE 2: Respondents' frequencies of spelling orthographic errors $(N=6)$.

Respondents committed a number of spelling errors. Seventyfive per cent of the respondents used numbers instead of words, $57 \%$ used poor sentence construction and $90 \%$ omitted some words in their essays.

\section{Discussion of findings}

The effect of WhatsApp language errors on writing was observed in the respondents' academic essay writing. Respondents wrote sentences using numbers instead of words and abbreviations. For example, some wrote ' $b f^{\prime}$ (before), '2 $\mathrm{dy}^{\prime}$ (today), '1 $\mathrm{tm}$ ' (first time). The orthographic errors throw light on the social constructivist notion of error analysis, which suggests that learners bring into the classroom concepts they may be using outside the classroom, for example on social media and cell phones. As they communicate in an informal manner on these platforms, the language used on WhatsApp is then internalised and reproduced by the respondents in their academic essays. Such writing by the respondents may suggest that they are using WhatsApp social media in their day-to-day life. Their informal language structures resurface in the formal written work as it did in the essays analysed for this study. The use of WhatsApp language by the respondents in the formal written essays made reading, understanding and marking of the work very difficult since the researcher had to try to decipher what the participant intended to say. Young (2009:56) states that another way of shortening communication in English is through the use of 'emoticons'. This is an intriguingly new and still evolving linguistic trend which tends to delight, annoy or puzzle people as they read a piece of work - as was observed by the researchers while they were reading the essays analysed for this article.

The negative effects of learners abbreviated writing in academic work, according to lecturers from the Ghana Academic Affairs Department of the Wa Polytechnic Registry (2006), were generally: poor (52\%), reflected reading problems (33\%) and delayed the script marking process (19\%). These issues negate the positive impact of text messaging as generalised. The use of phone abbreviations in texting also has a negative impact on grammar, as well as learners' writing in general (Chang, 2012). 
Similarly, the results in this article are closely related to those collected by Sarfraz (2011), who established that among the errors collected from essays, one unique error was identified which may likely open new areas of research in error analysis of English writing of non-native speakers. One of the respondents wrote 'lyf', and 'fite', in the essay and later on in the same essay these misspelled words appeared with the correct spellings ('life' and 'fight').

Currently, the reduced forms of words are frequently used for the short message service (SMS) and on the WhatsApp platform. This shows the negative influence of these technologies especially on second language learners who are committing unnecessary errors despite having the right understanding or at least a limited knowledge of rules of the target language. In the current study respondents used WhatsApp language, omitted words and used numbers where they needed to have used words in the essays they wrote. The negative effect of text messaging can only worsen the performance rating of students and therefore necessitates intervention to stop the language decay.

The above stance is supported by the Wa Polytechnic (2006) study. The researchers at Wa Polytechnic state that an appreciable number of students struggle with grammar, lexis and structure as a result of text messaging. This encourages abbreviation and non-conformity with grammatical rules. The researchers therefore contend that this could worsen students' written communication skills rather than improve them. The researcher of the current study found it very difficult to understand what the respondents were writing when using WhatsApp language in the essays they wrote. Such use of WhatsApp language was found to be common in the academic writing of essays and was felt to weaken the academic level of an essay, as it is informal and may even irritate a reader that such work was submitted. The researchers felt strongly that learners may need to be discouraged from the use of WhatsApp language by teachers at all times so that mastery of formal English language writing of essays should be encouraged, as learners need to be proficient in formal writing for academic and future career purposes.

Where the respondents used WhatsApp language to write their essays, they appeared very casual and resulted in a lack of interest in reading the work. Similarly, Young (2009) contends that some writing styles are increasingly overly casual and one should be hesitant to imitate them. Likewise, from the findings obtained from the survey conducted among Wa Polytechnic staff and students, it is evident that WhatsApp text messaging could pose a threat to student writing skills and therefore must be discouraged in student assignments and examinations. The written communication skills of learners are already generally poor; therefore, all efforts should be made to help students write correct and appropriate English in all communications.

Fourie's (2014) view is that the poor academic performance of learners who use chat 'lingo', acronyms and abbreviations can 'cross-contaminate' their academic reports, assignments and tests. This factor alters even their behaviour and affects their academic performance. Ironically, learners who choose to use WhatsApp excessively know that this activity may be influencing their behaviour and attention. WhatsApp certainly affects learners' academic performance when they are less aware of their poor language use in assignments and tests (Fourie 2014:86). The researchers can confirm that WhatsApp may influence learners essay writing skills, if not used correctly. The findings from the study showed the use of ' @', for example, in a sentence instead of 'at' indicating a 'cross-contamination' in learners academic writing.

\section{Conclusion}

A number of orthographic errors that have resulted from the use of WhatsApp seems to be predominant in learners' writing given the technologically advanced era of the 21st century. This article has shown that in applying error analysis, a number of errors in learners' writing can be attributed to the influence of WhatsApp messaging. The systematic analysis of these errors is very important. Error analysis serves as a linguistic analysis and it provides deep insight into the process of language learning. Error analysis also provides numerous solutions to various language learning-related problems. The findings of the present study on WhatsApp errors will empower language teachers as well as course and syllabus designers in designing teaching and learning materials that will help learners avoid these errors. By applying WhatsApp error analysis techniques and methodologies to make learners aware of the errors, educators would be able to make language teaching and learning more effective and assist learners in producing better written essays.

\section{Recommendations}

In the light of the findings of this research, the following recommendations are made:

- English FAL essay writing skills should be taught effectively to learners at all levels of learning in the classroom. To help learners recognise the modern WhatsApp errors, learners need to be given well-defined essay writing rules, for example planning, mind map, paragraphing, introduction, body and conclusion, and some samples of their written essays may need to be transcribed and distributed to them for correction and analysis so that they learn from their mistakes.

- English FAL learners need effective feedback about the WhatsApp errors along with appropriate remedial processes to curb the errors and monitor the recurring process as a conscious process to minimise errors. English language continues to carry the status of 'required to pass' in our schools, colleges, universities and the corporate workplace worldwide. From the data collected and analysed for this study, the level of English language proficiency of the learners may be said to be far from satisfactory. Correct writing of English ought to be a priority for learners and educators. 
- The Department of Basic Education should convene essay writing workshops at departmental level and at school level to educate and encourage teachers on how to teach and mark essays in order to help avoid these errors. English teachers in schools should be encouraged and empowered since their job description requires highly proficient English and proficiency in the conventions of formal written English in order to teach learners.

\section{Acknowledgements}

I hereby acknowledge Dr Songxaba, my supervisor, who worked day and night for the success of this article, my husband Mthandwa Sincuba, my daughter Nokulunga Sincuba, my son Mbongeni Sincuba and my niece Nosipho Ndlovu who had to do without me when I was working on this article. Most importantly I thank God for sustaining me throughout the journey of this article.

\section{Competing interests}

The authors declare that they have no financial or personal relationships that may have inappropriately influenced them in writing this article.

\section{Author's contributions}

S.L.S. offered guidance throughout the writing of this article. She was also responsible for the chronological arrangement of the subheadings and proofreading of each aspect of the article. L.S. is the main writer of the article. L.S. selected the topic, did the background literature search around the topic and conducted the research. The findings culminated in the writing of this article.

\section{Funding}

This research received no specific grant from any funding agency in the public, commercial, or not-for-profit sectors.

\section{Data availability statement}

Data sharing is not applicable to this article as no new data were created or analysed in this study.

\section{Disclaimer}

The views and opinions expressed in this article are those of the authors and do not necessarily reflect the official policy or position of any affiliated agency of the authors.

\section{References}

Akinwamide, T.K., 2012, 'The influence of process approach on English as second language students' performances in essay writing', ELT 5(3), 16-29. https://doi. org/10.5539/elt.v5n3p16
Allaith, Z.A. \& Joshi, R.M., 2011, 'Spelling performance of English consonants among students whose first language is Arabic', Reading and Writing 24(9), 1089-1110. https://doi.org/10.1007/s11145-010-9294-3

Allen, J.P.B. \& Corder, S.P., 1974, Techniques in applied linguistics: Language and learning, Oxford University Press, New York.

Babbie, E. \& Mouton, J., 2001, The practice of social research, Oxford Press, Cape Town. BBC Focus on Africa, 2006, The biggest African and International Stories from BBC.

Burke, J. \& Larry, C., 2008, Educational research: Quantitative, qualitative and mixed approaches, Sage, Los Angeles, CA.

Cai, L., 2001, 'Application of product teaching on college English writing', Journal of the Foreign Language World 4, 41-46.

Chang, Z., 2012, Student satisfaction, performance and knowledge construction in online collaborative learning, Information Science Publication, Hershey, PA.

Coons, S., 2012, 'Communication through social media: Its potential and pitfalls', Research Practitioner 13(2), 44-45.

Cunningworthy, A., 1995, Evaluating and selecting EFL teaching materials. Heinmeman, viewed 20 May 2016, from https://www.Readingmatrix.com/reaing-projects/ mejekiey/project.htmlpdf.

David, N., 2001, Second English teaching and learning, Foreign Language Teaching and Research Press, Beijing.

Davies, J., 2012, 'Facework on Facebook as a new literacy practice', Computers \& Education 59, 19-29. https://doi.org/10.1016/j.compedu.2011.11.007

Dovey, T., 2010, 'Facilitating writing from sources: A focus on both process and product', Journal of English for Academic Purposes 9, 45-60. https://doi.org/ 10.1016/j.jeap.2009.11.005

Department of Basic Education, 2015, Curriculum assessment policy grade 10-12, viewed 10 April 2017, from https://www.education.gov.za/Curriculum/ NationalCurriculumStatementsGradesR-12.aspx.

Fourie, S., 2014, An explorative investigation into the effect of frequent versus nonfrequent use of social network sites on students' spelling skill and academic performance, SAGE, Pretoria.

Franklin, T.S., 2014, 'Orthographic errors committed by sophomore students: A linguistic analysis', Mediterranean Journal of Social Sciences: Malaysia 5(23), 2439.

Habermas, J., 1979, 'What is universal pragmatics?', in T. McCarthy (ed.), Communication and the evolution of society, vol. 2, no. 5, pp. 1-68, Beacon, Boston, MA.

Jabeen, A., 2015, The role of error analysis in teaching and learning of second and foreign language, Pakistan, University of Gujarat.

James, C., 1998, Errors in language learning and use. Exploring error analysis, Longman, London, viewed 15 May 2016, from www.springerlink.com/index/ q1m7784588u51680.pdf.

Leedy, P.D. \& Ormrod, J.E., 2005, Practical research: Planning and design, 8th edn., Pearson, Prentice Hall, NJ.

Norrish, J., 1987, Language learners and their errors, Macmillan Publishers, New York.

Nesamalar, C., Saratha S. \& Teh, S.C., 2001, ELT methodology: Principles and practice, Penerbit Fajar Bakti, Selangor.

Njobe, M.W., 1992, An introduction to educational research, Unitra, Mthatha.

Padilla, A. \& McElroy, J.L., 2005, 'The tourism penetration index in large islands: The case of the Dominican Republic', Journal of Sustainable Tourism 13, 353-372. https://doi.org/10.1080/09669580508668562

Richards, J.C. \& Schmidt, R., 2002, Dictionary of language teaching \& applied linguistics, Pearson Education Limited, London.

Roelofse, L., 2013, 'Investigating the impact of FACEBOOK-speak on the written academic work of learners in a Western Cape high school', Faculty of Arts and Social Sciences, Department of General Linguistics, Stellenbosch University, viewed 10 May 2018, from http://scholar.sun.ac.za.

Sarfraz, S., 2011, Error analysis of the written English essays of Pakistani undergraduate students: A case study, Department of Sciences and Humanities, FAST-National University of Computer and Emerging Sciences Lahore Campus, Pakistan, vol. 01, number 03, pp. 71-75.

Songxaba, S.L., 2016, 'The use of Afrikaans-English-Xhosa code switching in the classroom', Scholars' Press, Saarbrucken, Germany.

Swain, M., 2005, 'The output hypo thesis: Theory and research', in E. Hinkel (ed.), Handbook of research in second language teaching and teaming, Lawrence Eribaum Associates, Mahwah, NJ.

Terre Blanche, M., Durheim, K. \& Painter, D., 2006, Research in practice: Applied methods for the social sciences, UCT Press, Cape Town.

Villareal, R. \& Van der Horst, A., 2008, 'Tourism competitiveness strategy of the Dominican Republic', Journal of Tourism Research 1(1), 14-28.

Wa Polytechnic, 2006, An investigation into the causes of poor performance of students in communication skills, A report submitted by the Communication Skills Committee to the Academic Board, viewed 06 March 2017, from http://www. mobilearn.org/download/results/guidelines.pdf.

Young, P., 2009, Writing and presenting in English: The Rosetta Stone of Science, Elsevier, London. 